\title{
Diabetes Care for Emerging Adults: Recommendations for Transition From Pediatric to Adult Diabetes Care Systems
}

\section{Citation}

Peters, Anne, and Lori Laffel. 2011. Diabetes care for emerging adults: recommendations for transition from pediatric to adult diabetes care systems. Diabetes Care 34(11): 2477-2485.

\section{Published Version}

doi:10.2337/dc11-1723

\section{Permanent link}

http://nrs.harvard.edu/urn-3:HUL.InstRepos:10578873

\section{Terms of Use}

This article was downloaded from Harvard University's DASH repository, and is made available under the terms and conditions applicable to Other Posted Material, as set forth at http:// nrs.harvard.edu/urn-3:HUL.InstRepos:dash.current.terms-of-use\#LAA

\section{Share Your Story}

The Harvard community has made this article openly available. Please share how this access benefits you. Submit a story.

Accessibility 


\section{Diabetes Care for Emerging Adults: Recommendations for Transition From Pediatric to Adult Diabetes Care Systems}

A position statement of the American Diabetes Association, with representation by the American College of Osteopathic Family Physicians, the American Academy of Pediatrics, the American Association of Clinical Endocrinologists, the American Osteopathic Association, the Centers for Disease Control and Prevention, Children with Diabetes, The Endocrine Society, the International Society for Pediatric and Adolescent Diabetes, Juvenile Diabetes Research Foundation International, the National Diabetes Education Program, and the Pediatric Endocrine Society (formerly Lawson Wilkins Pediatric Endocrine Society)

Anne Peters, mD, CDE ${ }^{1}$

LORI LAFFEL, MD, MPH ${ }^{2}$

the American Diabetes Association

Transitions Working Group*
D uring childhood and adolescence, there is a gradual shift from diabetes care supervised by parents and other adults to self-care management. The actual change from pediatric to adult health care providers signals a more abrupt change that requires preparation by patients, their families, and their health care providers. A number of publications from the U.S. and other countries have highlighted substantial gaps in care during this transition period between pediatric and adult care that often arise in later adolescence and the subsequent developmental stage of life termed "emerging adulthood." This is a critical time when patients not only assume responsibility for their diabetes self-care and interactions with the health care system but when they become more independent, potentially moving out of their parents' home to attend college or to join the workforce (1). In the context of these transitions and the developmental issues of this age-group, gaps in diabetes care can result in suboptimal health care utilization, deteriorating glycemic control, increased occurrence of acute complications, emergence of chronic complications of diabetes that may go undetected or untreated, and psychosocial, behavioral, and emotional challenges. With the increasing incidence of both type 1 and type 2 diabetes in childhood, adolescence, and young adulthood, there is an increase in the absolute numbers of youth with diabetes in this transition period,

From the ${ }^{1}$ University of Southern California Keck School of Medicine, Los Angeles, California; and the ${ }^{2}$ Joslin Diabetes Center, Harvard Medical School, Boston, Massachusetts.

Corresponding author: Lori Laffel, lori.laffel@joslin.harvard.edu.

DOI: $10.2337 / \mathrm{dcl} 1-1723$

*A complete list of the members of the American Diabetes Association Transitions Working Group can be found in the APPENDIX.

This position statement was peer-reviewed by members of the Professional Practice Committee in July 2011 and approved by the Executive Committee of the Board of Directors of the American Diabetes Association in August 2011

(c) 2011 by the American Diabetes Association. Readers may use this article as long as the work is properly cited, the use is educational and not for profit, and the work is not altered. See http://creativecommons.org/ licenses/by-nc-nd/3.0/ for details.

highlighting the need for a framework of care and education for this population and a call for additional research in this area.

Substantial challenges relating to the transitional period include the following:

- The dearth of empirical evidence on the best approaches to the transition process

- Fundamental differences in health care delivery between pediatric and adult health care providers

- Lack of well-defined criteria for determination of transition readiness

- The changing social and demographic characteristics of young adults that may influence their utilization of health care

- Gaps in health insurance during this transitional period

- Differences in learning styles between individuals in this transition period compared with both younger children and adults beyond the period of emerging adulthood

- Deficiencies in training of health care professionals in care delivery for emerging adults with diabetes

Most of the limited evidence base has focused on transitions in care for youth with type 1 diabetes. The recent emergence of type 2 diabetes in children and teenagers highlights an absolute deficiency of studies on transitioning youth with type 2 diabetes from pediatric to adult care (2). Although some medical and psychosocial issues may be different between these groups of youth with diabetes, many are assumed to be similar. 
In March 2010, the American Diabetes Association (ADA) convened a multidisciplinary group of experts and people with diabetes (see APPENDIX for organizations and individuals) to review the issues that confront both youth and young adults with diabetes and health care professionals during this critical transition process from pediatric to adult care. The issues that need to be considered to understand the process of transition were described and discussed. This resulting statement provides a framework for health care delivery during the transition period and an agenda for future research.

\section{RATES OF DIABETES DURING THE TRANSITION YEARS-The}

SEARCH for Diabetes in Youth study has estimated that about 15,000 youth are diagnosed annually with type 1 diabetes and about 3,700 are diagnosed annually with type 2 diabetes (3). In 2001, SEARCH estimated that there were approximately 154,000 youth under the age of 20 years with diabetes $(3,4)$, and in 2010 the estimated number of youth with diabetes was 215,000 , representing $0.26 \%$ of individuals in this age-group (5).

Worldwide, the prevalence of type 1 diabetes in children and young adults has doubled in the past 25 years and is expected to double yet again in the next 15-20 years, a phenomenon not observed several decades ago $(6,7)$. The epidemic of childhood obesity has lead to an increased incidence of type 2 diabetes being diagnosed in children and teenagers (8). Type 2 diabetes remains relatively uncommon in children under age 10 years, with the majority of cases identified in youth during the 2 nd decade of life and affecting predominantly those from racial and/or ethnic minority groups, namely American Indians, blacks, Hispanics, Asians, and Pacific Islanders (9-13). Furthermore, although the incidence of type 1 diabetes declines toward the middle to the late 2nd decade of life (age 15-19 years) from the peak rates observed during puberty in early adolescence, the incidence of type 2 diabetes continues to increase with age.

There are limited epidemiological data that span the age range from late adolescence through young adulthood (18-30 years of age), although there are data that precede and follow this key developmental period. The SEARCH study provides prevalence estimates for 15- to 19-yearolds in various racial and ethnic populations (9-13). Prevalence of type 1 diabetes for this age-group ranges from 0.43 per
1,000 in Navajo youth to 3.22 per 1,000 in non-Hispanic whites, while the prevalence of type 2 diabetes ranges from 0.29 (non-Hispanic whites) to 2.36 (Navajo) per 1,000 . In a survey of 11,855 young adults ( $41 \%$ response rate), ages $18-29$ years, attending 2-year and 4-year postsecondary educational institutions in Minnesota, $0.55 \%$ of students reported having a diagnosis of type 1 diabetes (E. Ehlinger, personal communication).

The size of the young adult population with diabetes is difficult to know with certainty. The overall numbers of children, adolescents, and young adults with diabetes in the U.S. in 2007 was estimated at close to a million in a study of diabetes costs including the age-groups $<18$ and 18-34 (14). Given the current estimates of the prevalence of diabetes in youth, one can expect that each year there are tens of thousands of emerging young adults with type 1 or type 2 diabetes who will be transitioning from pediatric to adult care.

\section{EMERGING ADULTHOOD-For}

the purposes of this statement, we have chosen to focus on the age range of 18-30 years. The preceding period of adolescent growth and development is a stage of tremendous physical, social, and emotional change that challenges diabetes management for both youth and health care providers. During this stage of adolescent development, there is a need for ongoing family involvement in diabetes management in order to reduce the risk of deterioration in glycemic control that often accompanies adolescence (15).

In contrast to the views of traditional developmental psychology, contemporary thinking is that young adulthood does not immediately follow adolescence, but begins when youth are in their late 20 s or early 30 s and that the developmental stage between ages $\sim 18$ and 30 years defines a period called emerging adulthood (16). Recent cultural trends in America suggest that young people in their 20s delay assuming adult roles with respect to marriage, parenting, and work compared with young adults in earlier generations. Contemporary developmental theorist J.J. Arnett (16) suggests that the postadolescent period is subdivided into an early phase corresponding to the years immediately after high school ( $\sim 18-24$ years) and a later phase when more traditional adult roles are assumed ( $\sim 25-30$ years). Thinking about the postadolescent period as consisting of two phases provides a valuable framework when considering diabetes management and may help to ensure that the clinician's approach and focus are appropriately matched to the emerging adult's life circumstances and readiness to become an active participant in his/her own diabetes management.

During the early phase of emerging adulthood, the person may be transitioning geographically, economically, and emotionally away from the parental home. Competing academic, economic, and social priorities often detract from a focused commitment to chronic disease management. Even as young adults face these competing demands, most do not believe that they have achieved all of the skills necessary to remain independent and accept these responsibilities on their own (16). Therefore, it may be unrealistic to expect the person with diabetes in the first phase of emerging adulthood to make major changes in their diabetes management strategies, or even to transition to a new adult diabetes health care provider. Conversely, for many this early phase is marked by feelings of invulnerability and a tendency to reject adult control, which may further limit receptiveness to recommendations for diabetes treatment.

During the second phase of the young adult period, the 25- to 30-year-old often has a maturing sense of identity and assumes adult-like roles in society, such as entering into stable intimate relationships or full-time employment. This phase, when the individual starts making plans about his/her future life, is often accompanied by a growing recognition of the importance of striving for better glycemic control and receptiveness to improving self-care behavior. Life partners can be important supports and agents for change, and a shared sense of investment in the future will often catalyze this change in self-care behavior. This period, when lifelong patterns of behavior are likely established, can be a critical window of opportunity for health care interventions.

\section{ISSUES IN THE TRANSITION BETWEEN PEDIATRIC AND ADULt DIABETES CARE-The} transition from pediatric to adult diabetes care represents a high-risk period for a person with diabetes, a perfect storm during which interruption of care is likely for multiple reasons. The young person is leaving what has often been a longterm, comfortable relationship with health care providers, sometimes without preparation or ready access to a subsequent provider. There are also multiple 
psychosocial adjustments during the postadolescent period of emerging adulthood that can be confounded by financial stressors. Poor glycemic control, the presence of risk factors for complications (hypertension and dyslipidemia), highrisk behaviors (cigarette smoking and drug and/or alcohol abuse), and emerging complications may further increase the difficulty of this period. The period of emerging adulthood may be accompanied by uncertainty regarding health insurance coverage upon completing education or leaving the parental home. Given that individuals in this transition period have had the highest rates of uninsurance or underinsurance in the past, the reforms of the Patient Protection and Accountable Care Act in the U.S. should be of particular benefit to emerging adults with chronic conditions such as diabetes.

The following sections elaborate on eight areas of particular relevance for the emerging young adult with diabetes: differences between pediatric and adult care, poor glycemic control, loss to follow-up care, acute complications, psychosocial issues, reproductive health issues, substance use and abuse, and chronic complications.

\section{Differences between pediatric and adult care}

There are fundamental differences in the approach and delivery of diabetes care between pediatric and adult patients. Diabetes care for pediatric patients requires involvement of the family in order to be successful. Young children do not have the cognitive ability to master diabetes management, and teens often do not possess the emotional maturity to sustain the tasks of daily therapy. Although health care delivery varies by system and access, in the pediatric health care setting, visits tend to be family-focused, holistic, and centered on management approaches that fit diabetes into the child and family's lifestyle. Diabetes visits and management approaches include parents/guardians as well as the youth.

In adult care, the focus is more on the autonomously functioning individual patient, who can be informed or counseled but then is expected to make his/her own choices about behavior or treatments. Adult visits tend to be substantially shorter and focused on medical problems. Adult patients choose who they do and do not want to have access to their health information and are largely considered independent consumers of health care. Whereas individuals change gradually from childhood to adulthood, the change in health care provider can be abrupt and unsettling, suggesting that a more gradual transition may be preferable.

\section{Poor control of glycemia and other risk factors}

There remains a considerable gap between the recommended glycemic control levels and the levels actually achieved in clinical practice, especially for older teens and young adults. The SEARCH for Diabetes in Youth study showed that only 32\% of youth with type 1 diabetes aged 1318 years and $18 \%$ of those aged $\geq 19$ years achieved ADA-recommended AlC targets (17). On the other hand, National Health and Nutrition Examination Survey data reveal that $56 \%$ of adults achieve target $\mathrm{AlC}$ values of $<7 \%$ (18). The greatest proportion of youth with type 1 or type 2 diabetes in poor glycemic control ( $\mathrm{AlC} \geq 9.5 \%$ ) were teenagers; one of every four patients aged $>12$ years had such elevated AlC levels (17). Others have documented poor glycemic control during the older teen and young adult years $(19,20)$. Those in the poorest glycemic control are at high risk for both acute complications and chronic microvascular complications $(20,21)$.

The prevalence of cardiovascular risk factors is much greater in youth with type 2 versus type 1 diabetes, regardless of ethnicity (22). However, as the general obesity rates among all U.S. children and adolescents increase, youth with type 1 diabetes have experienced similarly increasing rates and may have additional cardiovascular risk, partly as a result of the suboptimal diets reported in youth with either type 1 or type 2 diabetes (23). Studies show higher rates of dyslipidemia in obese children and adolescents with type 2 diabetes $(22,24,25)$. Elevated lipid levels in youth with type 1 diabetes appear to be related to level of glycemic control (26). The rates of hypertension in children and adolescents with diabetes compared with those without diabetes are largely related to overweight or obesity status. Fatty liver disease is also more common among obese children with insulin resistance and diabetes, may precede the diagnosis of type 2 diabetes, and has also been linked to type 1 diabetes (27). Progression and optimal treatment of fatty liver disease is not known in adolescents, but the disease can progress to cirrhosis and death. These risk factors need to be addressed in the adolescent and transitioning young adult.

\section{Loss to follow-up}

The competing distractions of young adult life often interfere with the requirements of successful diabetes management, including the need to maintain consistent medical care. Transitioning older teens and young adults are at high risk for disengagement from health care and, in turn, the emergence of complications that may go undetected without appropriate follow-up diabetes care and screening. There are adverse short-term (hypoglycemia, hyperglycemia, or diabetic ketoacidosis [DKA]) and long-term (nephropathy and retinopathy) outcomes when patients with diabetes are lost to follow-up or have infrequent encounters $(21,28,29)$. Rates of hospitalization and emergency use and costs of care are higher when glycemic control is poor (21). Glycemic control and diabetes outcomes are also poorer when patients do not understand or participate in their care.

The relative risk of death is higher for young adults with diabetes than for those without diabetes (30). Lapses in care or loss to follow-up accounts for some of these adverse outcomes of transitioning older teens and young adults (31-33). Older teens and young adults with diabetes, especially those from racial/ethnic minority or low socioeconomic status backgrounds, require increased access to care in order to maintain continuity and coordination of multidisciplinary support and to receive ongoing self-management support. Continuous follow-up helps reduce the need for costly, acute hospitalizations and provides for early intervention of chronic complications to optimize longterm health outcomes and functioning.

\section{Increased risk for acute complications}

A variety of factors may increase the risk of hypoglycemia and severe hyperglycemia or DKA in transitioning youth, including loss of parental supervision of diabetes care and reduced attendance at diabetes medical visits. The challenges of work and/or school often take precedence over diabetes care. Other lifestyle changes may include increases in alcohol consumption, changes in physical activity levels, varying motivation for self-care (as emerging young adults separate from parents), and differing dietary patterns from a more controlled family-home environment. Although data are lacking on the incidence of severe hypoglycemia and DKA during the early transition years, in the Diabetes Control and Complications Trial (DCCT) adolescents aged 13-17 years at study entry and 
20-24 years at study's end had a higher rate of severe hypoglycemia than adults (34). Rates of DKA in older adolescents are associated with nonadherence and poorer glycemic control (35).

Recent studies of continuous glucose monitoring (CGM) have assessed rates of overnight hypoglycemia in individuals aged 15-24 years, with nocturnal hypoglycemia documented during $8.8 \%$ of nights (36). Real-time CGM and sensoraugmented pumps have the potential to reduce the incidence of hypoglycemic events while improving AlC in those with type 1 diabetes, although poor adherence regarding consistent CGM usage during the adolescent and young adult years has been a major limiting factor (37).

\section{Psychosocial issues}

Psychosocial challenges are common during emerging adulthood, occur more often in those with diabetes compared with those without diabetes, and occur more commonly during emerging adulthood than during other stages of life. Living with diabetes often brings with it a broad range of diabetes-related distresses. Diabetes-specific stressors that occur frequently and interfere with effective selfcare include not having clear and concrete goals for diabetes care; feeling discouraged and overwhelmed with the diabetes regimen; uncomfortable interactions concerning diabetes with family, friends, or coworkers who do not have diabetes; feelings of guilt or anxiety about getting off track with diabetes self-care; and worrying about the future and the possibility of serious complications (38). Anxiety disorders, the most frequently diagnosed psychiatric disorder in the general population, can complicate living with and self-management of diabetes, for example when fear of injections triggers panic attacks, when symptoms of anxiety are confused with hypoglycemia, or when anxiety about hypoglycemia becomes unmanageable.

Depression or the presence of depressive symptoms is a well-known comorbid condition for individuals with diabetes. In addition to being a barrier to effective diabetes self-management, depression is linked to poor glycemic control (39) and diabetes complications (40). In adolescents with diabetes, including 18- to 20year-olds, 15-33\% report depressive symptoms $(41,42)$, while $23-35 \%$ of emerging adults (18-28 years of age) with diabetes do so (43). Recent data from the Treatment Options for type
2 Diabetes in Adolescents and Youth (TODAY) study document similar levels of depressive symptoms in adolescents with type 2 diabetes, with rates of clinically significant depressive symptoms exceeding 20\% in older adolescent females (44). In addition, depressive symptoms were inversely associated with quality of life. Recognizing the trajectories of depressive symptoms to worsen and impact physical and psychosocial well-being as older teens transition into young adulthood, it is important to monitor and refer older adolescents and young adults with type 1 or type 2 diabetes to appropriate mental health resources.

Adolescent and postadolescent young women with diabetes have 2.4 times the risk of developing an eating disorder than age-matched women without diabetes (45). Although disordered eating behaviors occur in both sexes, they are much more common in women than men. About $30 \%$ of all women taking insulin struggle with subclinical symptoms of disordered eating, such as restrictive eating, a preoccupation with weight and shape, feelings of guilt after eating, and strategic misuse of insulin for weight control (46). Up to $60 \%$ are trying to lose weight with unhealthy weight control behaviors (47), with some studies showing as many as $57 \%$ of adolescents and young adults involved in the particularly unhealthy weight control behavior of intentional insulin mismanagement (48-50). One survey of 11,855 Minnesota students attending 2-year and 4-year colleges or universities revealed that about twice as many students with type 1 diabetes had been diagnosed with anorexia or bulimia compared with students without type 1 diabetes (overall survey results at http:// www.bhs.umn.edu/surveys/index.htm; data on type 1 diabetes not displayed).

Clinically diagnosable eating disorders such as anorexia and bulimia as well as subclinical disordered eating attitudes and behaviors present a serious health risk to the emerging adult with diabetes. Disordered eating is associated with poor metabolic control, reduced adherence, depression, increased risk of DKA, and increased rates of microvascular complications in women with diabetes (20). Severe eating disorders, especially anorexia nervosa and purging through insulin omission, are life threatening, and such patients may require hospitalization on an inpatient eating disorders unit experienced in taking care of patients with type 1 diabetes. Disordered eating is not exclusive to youth with type 1 diabetes; $6 \%$ of a large cohort of adolescents with type 2 diabetes had clinical and 20\% had subclinical levels of binge eating behaviors associated with more extreme obesity, global eating disorders, depressive symptoms, and poorer quality of life (51).

In summary, eating disorders and affective disorders are especially serious in emerging adults who have diabetes because insulin omission, depression, anxiety, and fear of hypoglycemia interfere with diabetes self-care behavior during a time when these patients may have fallen between the cracks of the pediatric and adult health care systems. Moreover, longitudinal cohort studies have revealed that there is a subgroup of adolescents with serious mental health and behavior problems who continue to deteriorate as they enter their 20s, often with onset of microvascular complications and early mortality. Clinicians who care for emerging adults with type 1 diabetes need to evaluate the mental as well as the physical health history of their new patients and foster access to mental health providers for consultation and collaborative care for the diagnosis and treatment of eating disorders, depression, anxiety, and fear of hypoglycemia. The same principles hold for individuals with type 2 diabetes, although there are fewer published reports. Because the TODAY study is a longitudinal study of adolescents with type 2 diabetes, this investigation will provide important data on the onset, progression, and possible resolution of disordered eating behaviors and depression as these patients enter emerging adulthood (51).

\section{Sexual and reproductive health issues}

There is no reason to expect that emerging adults with diabetes will behave differently than their peers with respect to the potential for unintended pregnancies and acquisition of sexually transmitted infections. Thus, sexual behavior and reproductive health are important areas for discussion by both pediatric and adult care providers, even when the many medical issues related to diabetes and its complications tend to take precedence, delegating these issues to a secondary status.

Contraception needs to be addressed with adolescents and young women with diabetes-even more so than in women without diabetes-because of the need for reproductive planning in order to 
avoid unplanned pregnancies and maximize the outcomes of diabetic pregnancies. Contraceptive use to prevent pregnancy is lower among adults with diabetes aged $20-44$ years; $39 \%$ of those with diabetes were not current users of contraception compared with $27 \%$ of adults without diabetes (52). Among teens aged 13-19 years with diabetes, only $16 \%$ reported using birth control and, among those ever sexually active, 67\% had ever used birth control (53). An increasing number of young women with preexisting diabetes are becoming pregnant and delivering babies (54). Given that the highest pregnancy and birth rates occur in the 18- to 30-year-old age range, the importance of preconception counseling and care for individuals with type 1 and type 2 diabetes is clear. Fewer than one in four young women aged 16-20 years with diabetes were aware of maternal and fetal risks of pregnancy and of the need for good glycemic control in order to conceive and give birth to a healthy child (55). Although preconception care is often not a routine part of ongoing diabetes care, the development of a reproductive health plan as suggested by the Centers for Disease Control and Prevention Select Panel on Preconception Care is essential (http://www.cdc.gov/mmwr/preview/ mmwrhtml/rr5506al.htm).

\footnotetext{
Alcohol, smoking, and drug abuse Emerging adults with diabetes may risk their health by involvement in behaviors such as drinking alcohol and smoking cigarettes. Among samples of adolescents and emerging adults with diabetes, alcohol and tobacco use seem equivalent to rates in those without diabetes. Alcohol use worsens glycemic control (56) and is a known risk factor for severe hypoglycemia, while cigarette smoking increases cardiovascular risk and risk for microalbuminuria among adolescents and emerging adults with diabetes $(57,58)$. Involvement in these and other high-risk behaviors such as drug abuse places these youth at risk for immediate and long-term diabetes complications. In addition, such high-risk behaviors impinge upon the safety of the older adolescent and young adult who is beginning to drive. Risks of these behaviors as well as the risks associated with hypoglycemia while driving should be discussed. Abstinence from alcohol and substance use while driving should be directly discussed, and appropriate blood glucose monitoring along with prevention and treatment of hypoglycemia
}

before and during driving should be established.

\section{Emergence of signs of chronic diabetes complications}

Rates of clinically apparent diabetes complications are low in adolescents, although there is evidence of early microvascular complications. About $10 \%$ of adolescents with type 1 diabetes have microalbuminuria (59), whereas $\sim 30 \%$ of teens with type 2 diabetes have microalbuminuria (27); the SEARCH study has verified a threefold higher rate of microalbuminuria in youth with type 2 compared with those with type 1 diabetes (60). Higher rates of microalbuminuria and hypertension are seen in youth with type 2 than youth with type 1 diabetes, despite the fact that those with type 2 diabetes on average have shorter duration of disease (61). Retinopathy is rare among teens with type 1 diabetes, although more common than among teens with type 2 diabetes (61); data are forthcoming from the TODAY study regarding the rates of retinopathy among teens and young adults with type 2 diabetes to supplement the modest data currently available. When neuropathy testing is performed, $\sim 20 \%$ of adolescents with diabetes have evidence of peripheral sensory polyneuropathy and/or findings of autonomic neuropathy (61).

The beginnings of atherosclerotic disease occur in children and adolescents (62). Risk factors such as elevated LDL cholesterol level, reduced HDL cholesterol level, smoking, and higher AlC levels were associated with fatty streaks and raised intimal lesions in autopsy studies. Predictors of abnormal vessels in the Bogalusa Heart Study included high BMI, high total and LDL cholesterol, elevated triglycerides, and high systolic and diastolic blood pressure (63). Therefore, risk factors similar to those identified in older individuals impact the development of atherosclerosis in adolescents and young adults. The presence of diabetes is associated with elevated carotid artery intima-media thickness, stiffer blood vessels independent of lipids, and higher levels of inflammatory markers compared with nondiabetic individuals $(64,65)$.

Although pediatricians treat diabetes complications infrequently, adult physicians follow guidelines that are specifically written to address the complications of diabetes. Adult guidelines are often based on data from older adults, usually with type 2 diabetes; therefore, their application to younger individuals with type 1 diabetes needs to be individualized. Nonetheless, discussion of diabetesrelated complications and preparation of the transitioning older teen or young adult for changes in care practices should occur prior to transition.

\section{APPROACHES TO IMPROVE TRANSITIONS IN CARE}

\section{Previously published approaches on transitioning older teens and emerging adults with diabetes}

Teens and young adults require assistance with transition because they are a vulnerable population at risk for loss-to-followup care and poor health outcomes. Once transferred out of pediatric care, published reports provide evidence of gaps in follow-up care with a decrease in physician visits after transfer $(32,33,66)$. Patients with fragmented follow-up care demonstrated poorer glycemic control and a higher rate of hospitalization (67). Therefore, the goal of transition programs is to focus on easing the transfer process from pediatric to adult care providers.

There is substantial interest in identifying effective ways to transition older teens and young adults with diabetes to adult care providers. Much of the published literature on the topic describes observational studies or uncontrolled programs, and there are no published, empirically tested, randomized controlled trials of validated transition programs. Studies using patient interviews, questionnaire responses, or focus group discussions indicate that young adults describe time as a major challenge to maintaining contact with the diabetes health care team following transfer. Some reports have suggested evening hours or flexible clinics. Others have suggested a longer visit as the initial meeting with the adult provider, the provision of special clinic times that focus exclusively on teens to young adults up to age 30 years, and the need to provide the transitioning patient with written information regarding the transfer process and the new physician. This information is in addition to the medical summary of the patient's past diabetes health care that should be provided to the receiving physician. Most of these studies have substantial limitations because they reflect small sample sizes and particular health care delivery systems $(32,66,68,69)$. A recently published systematic review of the transition between pediatric and adult care identified only 10 studies across a spectrum of chronic diseases of childhood that evaluated particular 
interventions and associated outcomes (70). Of these studies, eight included patients with diabetes, one included patients with cystic fibrosis, and one included organ transplant recipients. The interventions targeted either the patient through education and skills training, staff through identification of coordinators or combined pediatric and adult team members, or delivered services through the creation of separate young adult clinics or enhanced after-hours phone support. While six of the studies reported improvements in either glycemic control, the occurrence of complications, or rates of follow-up visits and screening procedures, study methodologies varied, with only two studies using a controlled, comparison group design. Indeed, recent recommendations for the transition from pediatric to adult care for patients with cystic fibrosis focus on the preparation of the pediatric care providers, the training and availability of adult care providers versed in cystic fibrosis management, and assessment of transition readiness of pediatric patients and families rather than on empiric studies (71).

\section{Models of transition care}

There are a few published reports of transition care models that have been established in the U.K., Spain, Australia, and Canada. The U.K. model evaluated different systems varying from transfer to an adult clinic or different hospital, transition to a combination of pediatric and adult care providers, or transfer to a young adult clinic within the same pediatric hospital (33). The latter two approaches were associated with greater attendance at follow-up visits than the former. Other programs have included transition coordinators, sometimes referred to as patient navigators or care ambassadors, and other approaches that focused on transition education programs. The education programs included workshops aimed at preparing the transitioning teen. Some programs included monthly visits for the first 3-6 months in efforts to reduce loss to follow-up, while others used the transition coordinator to schedule and reschedule any missed appointments $(31,69)$. Future efforts need to standardize and empirically evaluate these various approaches with attention to assessing medical as well as psychosocial outcomes of care $(1,72)$. Additionally, there are settings, such as in family practice, where care can continue uninterrupted throughout the transitioning period.

Although there are a few observational studies addressing transitioning youth with type 1 diabetes $(69,73)$, there are essentially no studies on transitioning individuals with type 2 diabetes. Given that the number of youth with type 2 diabetes is increasing, this is an important area of study.

Programs need to be designed and evaluated that identify a transition coordinator (i.e., care ambassador or patient navigator) who reaches out to the transitioning emerging adult using multiple means (phone, mail, e-mail, text messaging, social media, etc.) to ensure timely follow-up visits. Another model that needs to be designed and evaluated for older transitioning adolescents is a special clinic in which both pediatric and adult providers are in attendance.

\section{OTHER ORGANIZATIONS' RECOMMENDATIONS FOR TRANSITION OF EMERGING} ADULTS WITH DIABETES-Many professional organizations have identified the need to provide guidelines to ease the transition from pediatric to adult care, though not specifically for youth with diabetes $(1,74)$. In 2002, the American Academy of Pediatrics, the American Academy of Family Physicians, and the American College of Physicians-American Society of Internal Medicine (75) released a policy statement that noted the goal of an effective transition plan is to provide developmentally appropriate health care services that continue uninterrupted as the individual moves from adolescence to adulthood. Similarly, in 2003, the Society for Adolescent Health and Medicine (76) published a position statement identifying the importance of organized and coordinated transition programs. These position statements along with a recent statement from the American Academy of Pediatrics (77) provide guidelines for the design and implementation of successful transition programs based upon published studies and expert opinion. Similarly, our committee created recommendations based upon published studies, models of transition across pediatric chronic diseases such as cystic fibrosis, published guidelines regarding the current recommendations for diabetes care for pediatric and adult patients, and expert opinion.

\section{ADA RECOMMENDATIONS FOR CARE TRANSITION OF EMERGING ADULTS WITH}

DIABETES-The ADA level-of-evidence grade, as shown in Table 1 , is provided in parentheses.

1. Pediatric health care providers, working collaboratively with the patient and family, should prepare the developing teen for the upcoming transition in health care delivery beginning at least 1 year prior to the transfer to adult health care providers, and likely during the early adolescent years. (E)

2. Preparation should include a more directed focus on diabetes self-management skills for the teen/emerging adult and his/her parents. There should be a gradual transfer of diabetes care responsibilities to the teen from the parent or guardian. Broadening responsibilities go beyond diabetes management tasks such as glucose self-monitoring and insulin administration and should include scheduling appointments and ensuring a proper supply of medications and supplies. Diabetes education should be redirected to the growing and developing teen rather than focused exclusively on the parents. (E)

3. Preparation should include information about the differences between pediatric and adult providers in their approaches to care, as well as education regarding health insurance options and how to maintain coverage. (E)

4. The pediatric provider should prepare and provide to both the patient and future adult care provider a written summary that includes an active problem list, compilation of medications, assessment of diabetes selfcare skills, summary of past glycemic control and diabetes related comorbidities, as well as a summary of any mental health problems and referrals during pediatric care. (E)

- The National Diabetes Education Program, a joint program of the Centers for Disease Control and Prevention and the National Institutes of Health, has developed a template that can be helpful (http://www.ndep. nih.gov/resources/presentations/ transition-slides-jg-aace-presentation03-22-10/index.aspx)

Table 1-ADA evidence grading system

A: Clear or supportive evidence from wellconducted randomized controlled trials or meta-analyses that incorporated quality ratings

B: Supportive evidence from well-conducted cohort or observational studies

C: Supportive evidence from poorly controlled or uncontrolled studies, or conflicting evidence with the weight of evidence supporting the recommendation

E: Expert consensus or clinical experience 
5. Health care providers need to recognize the vulnerability of emerging adults with diabetes to loss of consistent health care and difficulties in adhering to diabetes management due to competing psychosocial, educational, and vocational changes, leading to deteriorating glycemic control. Both pediatric and adult care providers should assist in providing support and links to resources that could benefit the patient. (B)

6. The transferring health care providers should provide emerging adults with specific referrals to adult care providers versed in the principles of intensive diabetes management to match the particular needs of the patients with type 1 or type 2 diabetes. One might consider creation of a directory of adult providers with expertise and interest in the care of young adults. (E)

7. The transferring providers should empower the emerging adults with links to resources that can help them reconnect to care should they become lost to follow-up. Consideration should be given to assisting the young adult with scheduling the first appointment with the adult care provider within 3-4 months of the final pediatric visit; a care ambassador or patient navigator can aid the transitioning young adult with follow-up to ensure timely visits. (C)

8. Care must be individualized and developmentally appropriate, with an emphasis on adherence to diabetes self-management and consistent use of glucose-lowering medications in order to prevent acute and long-term complications of diabetes. (B)

9. Emerging adults with diabetes should be evaluated and treated for disordered eating behaviors and affective disorders. It is important for the diabetes provider to have a mental health referral source who understands the fundamentals of working with individuals with diabetes. (C)

10. Ongoing visits should occur every 3 months for patients taking insulin and every 3-6 months for patients with type 2 diabetes not taking insulin, according to current ADA recommendations. (E)

11. Screening guidelines for microvascular and macrovascular complications in pediatric and adult patients with diabetes should be followed. (B)

12. Assessment of risk for macrovascular complications should begin in childhood according to guidelines for lipid screening, blood pressure assessment, and weight management. Management of lipids and hypertension should proceed according to pediatric and adult guidelines. (B)

13. Birth control, pregnancy planning and risks, prevention of sexually transmitted illnesses, use of alcohol and drugs, smoking, and driving should be discussed with the older teens and the emerging adults by both pediatric and adult providers with an emphasis on the interplay of these issues with diabetes. (E)

14. Both pediatric and adult providers should ensure that their patients with diabetes receive ongoing primary and preventive health care (usually separate from their ongoing diabetes specialty care) and, ideally, that the emerging adult feels that he/she is receiving accessible, patient-centered, coordinated, comprehensive, continuous, compassionate, and culturally effective care. (E)

\section{SUMMARY AND}

IMPLICATIONS-For emerging young adults with diabetes, it is particularly important to create effective and translatable processes for the transition in care from pediatric to adult providers in order to optimize well-being and health for the near term. It is additionally imperative for these young adults to achieve target glycemic control in order to prevent long-term complications and to maximize lifelong functioning. There are no proven strategies to achieve these goals, although programs that particularly target the young adult with diabetes through education, skills training, specialty transition clinics, or addition of transition coordinators appear to offer promise. Our current knowledge regarding this transition process calls for ongoing and expanding research initiatives, including the continued training and identification of adult providers versed not only in the medical care but also in the psychosocial needs of the young adult with diabetes. The next decade should see the emergence of evidence-based strategies that support best practice for the growing numbers of young adults with type 1 and type 2 diabetes who will be making this important transition.

Acknowledgments - The writing group meeting was supported by an unrestricted grant from the Jonas Brothers' Change for the Children Foundation.

A.P. currently serves on the speaker's bureau for Amylin, Lilly, Takeda, and Novo Nordisk and is a consultant for Amylin, Lilly, and Novo Nordisk. A.P. also participated in ad hoc speaking engagements and served as a consultant in 2010 for AstraZeneca, Abbott Diabetes Care, Boehringer Ingelheim, Bristol-Myers Squibb, Dexcom, Medtronic MiniMed, Merck, Roche, and sanofi-aventis. L.L. has received grant support from Bayer and served as a consultant for Johnson \& Johnson, Lilly, sanofi-aventis, BristolMyers Squibb, and Menarini. No other potential conflicts of interest relevant to this article were reported.

APPENDIX - Members of the American Diabetes Association Transitions Working Group are Ann Albright, PhD, RD*, Centers for Disease Control and Prevention, Atlanta, Georgia; Barbara Anderson, PhD, Baylor College of Medicine, Houston, Texas; Zachary T. Bloomgarden, MD, Mount Sinai School of Medicine, New York, New York; Belinda Childs, ARNP, MN, CDE, BC-AD, Mid-America Diabetes Association, Wichita, Kansas; Edward Ehlinger, MD, MSPH, Boynton Health Service University of Minnesota (now Commission of Minnesota Department of Public Health), St. Paul, Minnesota; Kathleen M. Hanna, PhD, RN, Indiana University, Indianapolis, Indiana; Irl B. Hirsch, MD, University of Washington, Seattle, Washington; Marissa Hitchcock, BSN, RN, University of South Florida, Tampa, Florida; Jean M. Lawrence, ScD, MPH, MSSA, Kaiser Permanente Southern California, Pasadena, California; Shannon P. Lyles, BSN, RN, CDE, University of Florida, Jacksonville, Florida; Sue McLaughlin, MOL, BS, RD, CDE, Nebraska Medical Center, Omaha, Nebraska; Gnanagurudasan Prakasam, MD, MRCP, MHA, Sutter Medical Center, Sacramento, California; Michael Riddell, PhD, York University, Toronto, Ontario, Canada; Henry Rodriguez, MD, University of South Florida, Tampa, Florida; Jay Shubrook, DO, Ohio University, Athens, Ohio; Janet Silverstein, MD, University of Florida, Jacksonville, Florida; Sue Kirkman, MD, ADA, Alexandria, Virginia; Jennifer Puryear, MPH, ADA, Alexandria, Virginia.

* The findings and conclusions mentioned in this article are those of the author and do not necessarily reflect the official position of the Centers for Disease Control and Prevention.

\section{References}

1. Weissberg-Benchell J, Wolpert H, Anderson BJ. Transitioning from pediatric to adult care: a new approach to the post-adolescent 
young person with type 1 diabetes. Diabetes Care 2007;30:2441-2446

2. American Diabetes Association. Type 2 diabetes in children and adolescents. Diabetes Care 2000;23:381-389

3. Dabelea D, Bell RA, D'Agostino RB Jr, et al.; Writing Group for the SEARCH for Diabetes in Youth Study Group. Incidence of diabetes in youth in the United States. JAMA 2007;297:2716-2724

4. Liese AD, D'Agostino RB Jr, Hamman RF, et al.; SEARCH for Diabetes in Youth Study Group. The burden of diabetes mellitus among US youth: prevalence estimates from the SEARCH for Diabetes in Youth Study. Pediatrics 2006;118:1510-1518

5. Centers for Disease Control and Prevention. National Diabetes Fact Sheet: National Estimates and General Information on Diabetes and Prediabetes in the United States, 2011. Atlanta, GA, U.S. Department of Health and Human Services, Centers for Disease Control and Prevention, 2011

6. Harjutsalo V, Sjöberg L, Tuomilehto J. Time trends in the incidence of type 1 diabetes in Finnish children: a cohort study. Lancet 2008:371:1777-1782

7. Patterson CC, Dahlquist GG, Gyürüs E, Green A, Soltész G; EURODIAB Study Group. Incidence trends for childhood type 1 diabetes in Europe during 1989. 2003 and predicted new cases 2005-20: a multicentre prospective registration study. Lancet 2009;373:2027-2033

8. Pinhas-Hamiel O, Zeitler P. The global spread of type 2 diabetes mellitus in children and adolescents. J Pediatr 2005;146:693-700

9. Lawrence JM, Mayer-Davis EJ, Reynolds K, et al.; SEARCH for Diabetes in Youth Study Group. Diabetes in Hispanic American youth: prevalence, incidence, demographics, and clinical characteristics: the SEARCH for Diabetes in Youth Study. Diabetes Care 2009;32(Suppl. 2):S123-S132

10. Dabelea D, DeGroat J, Sorrelman C, et al.; SEARCH for Diabetes in Youth Study Group. Diabetes in Navajo youth: prevalence, incidence, and clinical characteristics: the SEARCH for Diabetes in Youth Study. Diabetes Care 2009;32(Suppl. 2):S141-S147

11. Mayer-Davis EJ, Beyer J, Bell RA, et al.; SEARCH for Diabetes in Youth Study Group. Diabetes in African American youth: prevalence, incidence, and clinical characteristics: the SEARCH for Diabetes in Youth Study. Diabetes Care 2009;32 (Suppl. 2):S112-S122

12. Liu LL, Yi JP, Beyer J, et al.; SEARCH for Diabetes in Youth Study Group. Type 1 and Type 2 diabetes in Asian and Pacific Islander U.S. youth: the SEARCH for Diabetes in Youth Study. Diabetes Care 2009;32(Suppl. 2):S133-S140

13. Bell RA, Mayer-Davis EJ, Beyer JW, et al.; SEARCH for Diabetes in Youth Study Group. Diabetes in non-Hispanic white youth: prevalence, incidence, and clinical characteristics: the SEARCH for Diabetes in Youth Study. Diabetes Care 2009;32 (Suppl. 2):S102-S111

14. American Diabetes Association. Economic costs of diabetes in the U.S. In 2007. Diabetes Care 2008;31:596-615

15. Laffel LM, Vangsness L, Connell A, Goebel-Fabbri A, Butler D, Anderson BJ. Impact of ambulatory, family-focused teamwork intervention on glycemic control in youth with type 1 diabetes. J Pediatr 2003; 142:409-416

16. Arnett JJ. Emerging adulthood. A theory of development from the late teens through the twenties. Am Psychol 2000; 55:469-480

17. Petitti DB, Klingensmith GJ, Bell RA, et al.; SEARCH for Diabetes in Youth Study Group. Glycemic control in youth with diabetes: the SEARCH for diabetes in Youth Study. J Pediatr 2009;155:668-672, el-e3

18. Hoerger TJ, Segel JE, Gregg EW, Saaddine JB. Is glycemic control improving in U.S. adults? Diabetes Care 2008;31:81-86

19. Bryden KS, Dunger DB, Mayou RA, Peveler RC, Neil HA. Poor prognosis of young adults with type 1 diabetes: a longitudinal study. Diabetes Care 2003;26:1052-1057

20. Nathan DM, Zinman B, Cleary PA, et al.; Diabetes Control and Complications Trial/ Epidemiology of Diabetes Interventions and Complications (DCCT/EDIC) Research Group. Modern-day clinical course of type 1 diabetes mellitus after 30 years' duration: the diabetes control and complications trial/epidemiology of diabetes interventions and complications and Pittsburgh epidemiology of diabetes complications experience (1983-2005). Arch Intern Med 2009;169:1307-1316

21. Rewers A, Chase HP, Mackenzie T, et al. Predictors of acute complications in children with type 1 diabetes. JAMA 2002; 287:2511-2518

22. Rodriguez BL, Fujimoto WY, Mayer-Davis EJ, et al. Prevalence of cardiovascular disease risk factors in U.S. children and adolescents with diabetes: the SEARCH for diabetes in youth study. Diabetes Care 2006;29:1891-1896

23. Mayer-Davis EJ, Nichols M, Liese AD, et al. SEARCH for Diabetes in Youth Study Group. Dietary intake among youth with diabetes: the SEARCH for Diabetes in Youth Study. J Am Diet Assoc 2006;106: 689-697

24. Kershnar AK, Daniels SR, Imperatore G, et al. Lipid abnormalities are prevalent in youth with type 1 and type 2 diabetes: the SEARCH for Diabetes in Youth Study. J Pediatr 2006;149:314-319

25. Liu LL, Lawrence JM, Davis C, et al.; SEARCH for Diabetes in Youth Study Group. Prevalence of overweight and obesity in youth with diabetes in USA: the SEARCH for Diabetes in Youth study. Pediatr Diabetes 2010;11:4-11

26. Guy J, Ogden L, Wadwa RP, et al. Lipid and lipoprotein profiles in youth with and without type 1 diabetes: the SEARCH for Diabetes in Youth case-control study. Diabetes Care 2009;32:416-420

27. Copeland KC, Zeitler P, Geffner M, et al.; TODAY Study Group. Characteristics of adolescents and youth with recent-onset type 2 diabetes: the TODAY cohort at baseline. J Clin Endocrinol Metab 2011; 96:159-167

28. Krolewski AS, Warram JH, Christlieb AR, Busick EJ, Kahn CR. The changing natural history of nephropathy in type I diabetes. Am J Med 1985;78:785-794

29. Jacobson AM, Hauser ST, Willett J, Wolfsdorf JI, Herman L. Consequences of irregular versus continuous medical follow-up in children and adolescents with insulin-dependent diabetes mellitus. J Pediatr 1997;131:727-733

30. Laing SP, Swerdlow AJ, Slater SD, et al. The British Diabetic Association Cohort Study, I: all-cause mortality in patients with insulin-treated diabetes mellitus. Diabet Med 1999;16:459-465

31. Pacaud D, Yale JF, Stephure D, Dele-Davies $\mathrm{H}$. Problems in transition from pediatric care to adult care for individuals with diabetes. Can J Diabetes 2005;40:29-35

32. Busse FP, Hiermann P, Galler A, et al. Evaluation of patients' opinion and metabolic control after transfer of young adults with type 1 diabetes from a pediatric diabetes clinic to adult care. Horm Res 2007;67:132-138

33. Sparud-Lundin C, Ohrn I, Danielson E, Forsander G. Glycaemic control and diabetes care utilization in young adults with Type 1 diabetes. Diabet Med 2008; 25:968-973

34. Diabetes Control and Complications Trial Research Group. Effect of intensive diabetes treatment on the development and progression of long-term complications in adolescents with insulin-dependent diabetes mellitus: Diabetes Control and Complications Trial. J Pediatr 1994;125:177-188

35. Morris AD, Boyle DI, McMahon AD, Greene SA, MacDonald TM, Newton RW. Adherence to insulin treatment, glycaemic control, and ketoacidosis in insulin-dependent diabetes mellitus. The DARTS/MEMO Collaboration. Diabetes Audit and Research in Tayside Scotland. Medicines Monitoring Unit. Lancet 1997; 350:1505-1510

36. Juvenile Diabetes Research Foundation Continuous Glucose Monitoring Study Group. Prolonged nocturnal hypoglycemia is common during 12 months of continuous glucose monitoring in children and adults with type 1 diabetes. Diabetes Care 2010;33:1004-1008

37. Tamborlane WV, Beck RW, Bode BW, et al.; Juvenile Diabetes Research Foundation Continuous Glucose Monitoring Study Group. Continuous glucose monitoring and intensive treatment of type 1 diabetes. N Engl J Med 2008;359:1464-1476 
38. Polonsky WH, Anderson BJ, Lohrer PA, et al. Assessment of diabetes-related distress. Diabetes Care 1995;18:754-760

39. Lustman PJ, Anderson RJ, Freedland KE, de Groot M, Carney RM, Clouse RE. Depression and poor glycemic control: a meta-analytic review of the literature. Diabetes Care 2000;23:934-942

40. de Groot M, Anderson R, Freedland KE, Clouse RE, Lustman PJ. Association of depression and diabetes complications: a metaanalysis. Psychosom Med 2001;63:619-630

41. Lawrence JM, Standiford DA, Loots B, et al.; SEARCH for Diabetes in Youth Study. Prevalence and correlates of depressed mood among youth with diabetes: the SEARCH for Diabetes in Youth study. Pediatrics 2006;117:1348-1358

42. Hood KK, Huestis S, Maher A, Butler D, Volkening L, Laffel LM. Depressive symptoms in children and adolescents with type 1 diabetes: association with diabetesspecific characteristics. Diabetes Care 2006; 29:1389-1391

43. Hislop AL, Fegan PG, Schlaeppi MJ, Duck M, Yeap BB. Prevalence and associations of psychological distress in young adults with Type 1 diabetes. Diabet Med 2008; 25:91-96

44. Anderson BJ, Edelstein S, Abramson NW, et al. Depressive symptoms and quality of life in adolescents with type 2 diabetes: baseline data from the TODAY study. Diabetes Care 2011;34:2205-2207

45. Jones JM, Lawson ML, Daneman D, Olmsted MP, Rodin G. Eating disorders in adolescent females with and without type 1 diabetes: cross sectional study. BMJ 2000;320:1563-1566

46. Polonsky WH, Anderson BJ, Lohrer PA, Aponte JE, Jacobson AM, Cole CF. Insulin omission in women with IDDM. Diabetes Care 1994;17:1178-1185

47. Neumark-Sztainer D, Patterson J, Mellin A, et al. Weight control practices and disordered eating behaviors among adolescent females and males with type 1 diabetes: associations with sociodemographics, weight concerns, familial factors, and metabolic outcomes. Diabetes Care 2002;25:1289-1296

48. Rydall AC, Rodin GM, Olmsted MP, Devenyi RG, Daneman D. Disordered eating behavior and microvascular complications in young women with insulindependent diabetes mellitus. N Engl J Med 1997;336:1849-1854

49. Bryden KS, Neil A, Mayou RA, Peveler RC, Fairburn CG, Dunger DB. Eating habits, body weight, and insulin misuse. A longitudinal study of teenagers and young adults with type 1 diabetes. Diabetes Care 1999;22:1956-1960

50. Peveler RC, Bryden KS, Neil HA, et al. The relationship of disordered eating habits and attitudes to clinical outcomes in young adult females with type 1 diabetes. Diabetes Care 2005;28:84-88
51. Wilfley D, Berkowitz R, Goebel-Fabbri A, et al.; TODAY Study Group. Binge eating, mood, and quality of life in youth with type 2 diabetes: baseline data from the today study. Diabetes Care 2011;34:858-860

52. Vahratian A, Barber JS, Lawrence JM, Kim C. Family-planning practices among women with diabetes and overweight and obese women in the 2002 National Survey For Family Growth. Diabetes Care 2009; 32:1026-1031

53. Schwarz EB, Sobota M, CharronProchownik D. Perceived access to contraception among adolescents with diabetes: barriers to preventing pregnancy complications. Diabetes Educ 2010;36:489-494

54. Lawrence JM, Contreras R, Chen W, Sacks DA. Trends in the prevalence of preexisting diabetes and gestational diabetes mellitus among a racially/ethnically diverse population of pregnant women, 19992005. Diabetes Care 2008;31:899-904

55. Charron-Prochownik D, Sereika SM, Wang SL, et al. Reproductive health and preconception counseling awareness in adolescents with diabetes: what they don't know can hurt them. Diabetes Educ 2006;32:235-242

56. Glasgow AM, Tynan D, Schwartz R, et al. Alcohol and drug use in teenagers with diabetes mellitus. J Adolesc Health 1991;12:11-14

57. Reynolds K, Liese AD, Anderson AM, et al. Prevalence of tobacco use and association between cardiometabolic risk factors and cigarette smoking in youth with type 1 or type 2 diabetes mellitus. J Pediatr 2011; 158:594-601, el

58. Scott LJ, Warram JH, Hanna LS, Laffel LM, Ryan L, Krolewski AS. A nonlinear effect of hyperglycemia and current cigarette smoking are major determinants of the onset of microalbuminuria in type $1 \mathrm{di}$ abetes. Diabetes 2001;50:2842-2849

59. Alleyn CR, Volkening LK, Wolfson J, Rodriguez-Ventura A, Wood JR, Laffel LM. Occurrence of microalbuminuria in young people with Type 1 diabetes: importance of age and diabetes duration. Diabet Med 2010;27:532-537

60. Maahs DM, Snively BM, Bell RA, et al. Higher prevalence of elevated albumin excretion in youth with type 2 than type 1 diabetes: the SEARCH for Diabetes in Youth study. Diabetes Care 2007;30:2593-2598

61. Eppens MC, Craig ME, Cusumano J, et al. Prevalence of diabetes complications in adolescents with type 2 compared with type 1 diabetes. Diabetes Care 2006;29:1300-1306

62. McGill HC Jr, McMahan CA, Zieske AW, et al.; The Pathobiological Determinants of Atherosclerosis in Youth (PDAY) Research Group. Associations of coronary heart disease risk factors with the intermediate lesion of atherosclerosis in youth. Arterioscler Thromb Vasc Biol 2000;20:1998-2004

63. Li S, Chen W, Srinivasan SR, et al. Childhood cardiovascular risk factors and carotid vascular changes in adulthood: the Bogalusa Heart Study. JAMA 2003;290:2271-2276
64. Järvisalo MJ, Putto-Laurila A, Jartti L, et al. Carotid artery intima-media thickness in children with type 1 diabetes. Diabetes 2002;51:493-498

65. Haller MJ, Samyn M, Nichols WW, et al. Radial artery tonometry demonstrates arterial stiffness in children with type 1 diabetes. Diabetes Care 2004:27:2911-2917

66. Pacaud D, Yale JF. Exploring a black hole: Transition from paediatric to adult care services for youth with diabetes. Paediatr Child Health (Oxford) 2005;10:31-34

67. Nakhla M, Daneman D, To T, Paradis G, Guttmann A. Transition to adult care for youths with diabetes mellitus: findings from a Universal Health Care System. Pediatrics 2009;124:e1134-e1141

68. Insabella G, Grey M, Knafl G, Tamborlane $\mathrm{W}$. The transition to young adulthood in youth with type 1 diabetes on intensive treatment. Pediatr Diabetes 2007;8:228-234

69. Van Walleghem N, Macdonald CA, Dean HJ. Evaluation of a systems navigator model for transition from pediatric to adult care for young adults with type 1 diabetes. Diabetes Care 2008;31:1529-1530

70. Crowley R, Wolfe I, Lock K, McKee M. Improving the transition between paediatric and adult healthcare: a systematic review. Arch Dis Child 2011;96:548-553

71. Tuchman LK, Schwartz LA, Sawicki GS, Britto MT. Cystic fibrosis and transition to adult medical care. Pediatrics 2010;125:566-573

72. Nakhla M, Daneman D, Frank M, Guttmann A. Translating transition: a critical review of the diabetes literature. J Pediatr Endocrinol Metab 2008;21:507-516

73. Holmes-Walker DJ, Llewellyn AC, Farrell K. A transition care programme which improves diabetes control and reduces hospital admission rates in young adults with Type 1 diabetes aged 15-25 years. Diabet Med 2007;24:764-769

74. Court JM, Cameron FJ, Berg-Kelly K, Swift PG. Diabetes in adolescence. Pediatr Diabetes 2009;10(Suppl. 12):185-194

75. American Academy of Pediatrics; American Academy of Family Physicians; American College of Physicians-American Society of Internal Medicine. A consensus statement on health care transitions for young adults with special health care needs. Pediatrics 2002;110:1304-1306

76. Rosen DS, Blum RW, Britto M, Sawyer SM, Siegel DM; Society for Adolescent Medicine. Transition to adult health care for adolescents and young adults with chronic conditions: position paper of the Society for Adolescent Medicine. J Adolesc Health 2003;33:309-311

77. Cooley WC, Sagerman PJ; American Academy of Pediatrics; American Academy of Family Physicians; American College of Physicians; Transitions Clinical Report Authoring Group. Supporting the health care transition from adolescence to adulthood in the medical home. Pediatrics 2011;128:182-200 